\title{
Construção de significados e interação com, no e pelo computador: estudos problematizados no AVEA Moodle sobre uso das tecnologias da informação e comunicação
}

\author{
Cláudia Smaniotto Barin ${ }^{1}$, Liziany Müller ${ }^{1}$, Ricardo Machado Ellensohn² \\ ${ }^{1}$ Núcleo de Tecnologia Educacional - Universidade Federal de Santa Maria
}

${ }^{2}$ Curso de Química - Instituto Federal de Educação, Ciência e Tecnologia Farroupilha Panambi.

\begin{abstract}
The investigative focus of this work constitute the technology fluency problematized in the complementary discipline, Natural and Exact Sciences, at undergraduate level, mediated by network educational technologies, offered on the Physics, Geography and Chemistry's teachers at undergraduate level, at Universidade Federal de Santa Maria, as indispensable element for the use of communication and information technologies (CIT) in Knowledge's transformation in dialogical problematizing formative spaces and significance construction. Regarding to the methodology was developed an action-research using survey tools during elaboration, implementation, analysis and replanning of the discipline. Based on results is possible emphasize the absence of systematic orientation for the use of educations technologies under the transforming and generative of news knowledge perspective. The conclusive proposition is that the success in the integration of the technologies on the teaching-learning process requires planning, fluency, problematization, interaction/interactivity and incentive to autonomy.
\end{abstract}

Resumo. O foco investigativo deste trabalho se constitui na fluência tecnológica problematizada na disciplina complementar de graduação: Ciências Naturais e Exatas mediada por tecnologias educacionais em rede, ofertada nos Cursos de licenciatura em Física, Geografia e Química da Universidade $X X X$, como elemento imprescindivel para o uso das tecnologias da informação e comunicação na transformação de saberes em espaços formativos dialógico-problematizadores e de construção de significados. Metodologicamente desenvolveu-se pesquisa-ação com ferramentas survey durante elaboração, implementação, análise e replanejamento da disciplina. Como resultado destaca-se a ausência de orientação sistemática para o uso das tecnologias educacionais numa perspectiva transformadora e produtora 
de novos saberes. A proposição conclusiva é que o sucesso na integração das tecnologias no ensino-aprendizagem requer planejamento, fluência, problematização, interação/interatividade e incentivo à autonomia.

Palavras-chave: tecnologias da informação, fluência tecnológica; formação de professores; ensino-aprendizagem.

\section{Introdução}

As Tecnologias da Informação e da Comunicação (TIC) tem influenciado os modelos universitários de formação especialmente nos campos da pesquisa curricular e produção de recursos educacionais (Zabalsa, 2003 in apud Ramos; Nevado; Del Pino, 2006). No entanto além de valorizar as potencialidades presentes nas tecnologias em rede como, como a mídia interativa, é necessário superar esta visão e ampliar a reflexão, compreendendo os limites e potencialidades das tecnologias digitais como campo de construção do saber, com implicações no mundo do trabalho, das relações sociais e educacionais.

No campo de trabalho educacional, de produção do saber, as TIC assumem caráter central da mediação exigindo um novo profissional, com novas habilidades e competências. Entretanto, a utilização das TIC numa perspectiva transformadora não combina com o atual currículo de grande parte dos cursos de formação de professores, onde os conteúdos são organizados em "conteiners" (disciplinas) de forma fragmentada e desconexa da realidade do futuro profissional, onde nem mesmo as disciplinas de caráter formativo e as disciplina de caráter pedagógico se comunicam.

Assim, considerando as questões históricas e estruturais relacionadas à Educação e à Tecnologia, a discussão contemporânea apresenta um novo paradigma, a partir do momento em que alguns modelos tradicionais nas instituições de ensino começam a ficar ultrapassados e a compreensão dos processos de produção do conhecimento mediado pelas tecnologias - adquirem outros sentidos (França, 2009). Há um novo panorama educacional emergente em virtude do advento das TIC na educação, em diferentes experiências e ampliações metodológicas para esta esfera, estas tecnologias estão transformando, de forma significativa, a maneira de agir e refletir na educação (Soffa; Torres, 2009).

Segundo Moran (2000, p.27) um dos eixos da mudança na educação passa pela sua transformação em um processo de comunicação autêntica e aberta entre professores e estudantes. Esta afirmativa é corroborada por Levy (2008), que aponta que a utilização da tecnologia deve considerar a necessidade de atender uma geração que delibera por mudanças urgentes nos sistemas educacionais e nos papéis que desempenham o professor e o estudante.

O uso das tecnologias na educação tem provocado vários questionamentos a respeito dos métodos de ensino utilizados. Barros (2007, p. 105 e 106), as aulas dadas tradicionalmente estão gerando desinteresse e atualização de informações pelas tecnologias por parte dos alunos, o que está abalando o conhecimento "inquestionável' 
dos docentes, sendo assim, o "grande desafio consiste em integrar os professores com a cultura tecnológica para o processo de ensino e aprendizagem". Isso serve de indicador para afirmar que o professor deve ter fluência com as ferramentas tecnológicas sabendo o que elas oferecem em potencial e como podem ser exploradas em diferentes situações educacionais (Valente, 2001).

Muito se tem discutido acerca das potencialidades dos ambientes virtuais de ensino-aprendizagem (AVEA) na mediação da aprendizagem presencial, híbrida ou a distância. Para que o AVEA possa transformar o processo de ensino-aprendizagem, o mesmo precisa ser planejado e organizado de forma a flexibilizar a aprendizagem significativa ao estudante, despertando o interesse em aprender e promovendo a internalização de conceitos construídos. Isso, no entanto, não garante que as práticas escolares estejam sendo inovadoras em sua totalidade. Porém, implicam um desafio imediato, que é a melhoria nos índices de fluência tecnológica para que se possa explorar cada vez mais o potencial educacional (interatividade, interação e colaboração) das ferramentas.

A formação de professores para o uso das TIC encontra uma complexa rede de possibilidades e necessidades que vai sendo tecida a partir do imbricamento das novas tecnologias, que evoluem constantemente na sociedade da informação; dos sujeitos da aprendizagem, normalmente familiarizados com esse avanço tecnológico de forma mais afinca que o próprio professor; da leitura crítica da sociedade e do papel da escola na formação do cidadão. Assim o desafio que se apresenta é a formação inicial e continuada de professores capaz de promover para além de conhecimentos específicos de natureza científica e pedagógica, a autonomia, criatividade, reflexão crítica, espírito colaborativo, empreendedorismo, autonomia e a fluência tecnológica.

Diante do acima exposto, o foco investigativo deste trabalho se constitui na fluência tecnológica problematizada na disciplina complementar de graduação: Ciências Naturais e Exatas mediada por tecnologias educacionais em rede, ofertada nos Cursos de Física, Geografia e Química da Universidade XXXX como elemento imprescindível para o uso das TIC como elemento de transformação de saberes em espaços formativos dialógico-problematizadores e de construção de significados.

\section{Construção Metodológica}

O trabalho foi desenvolvido na Universidade Federal de Santa Maria, na cidade de Santa Maria, RS, Brasil, na disciplina de Ciências Naturais e Exatas mediadas por Tecnologias Educacionais em Rede.

A metodologia utilizada foi a pesquisa-ação, num paradigma construtivista de uma pesquisa qualitativa, a qual implica uma interação do pesquisador com seus sujeitos de investigação para a análise da realidade encontrada e para a construção de conhecimento (Figura 1). 


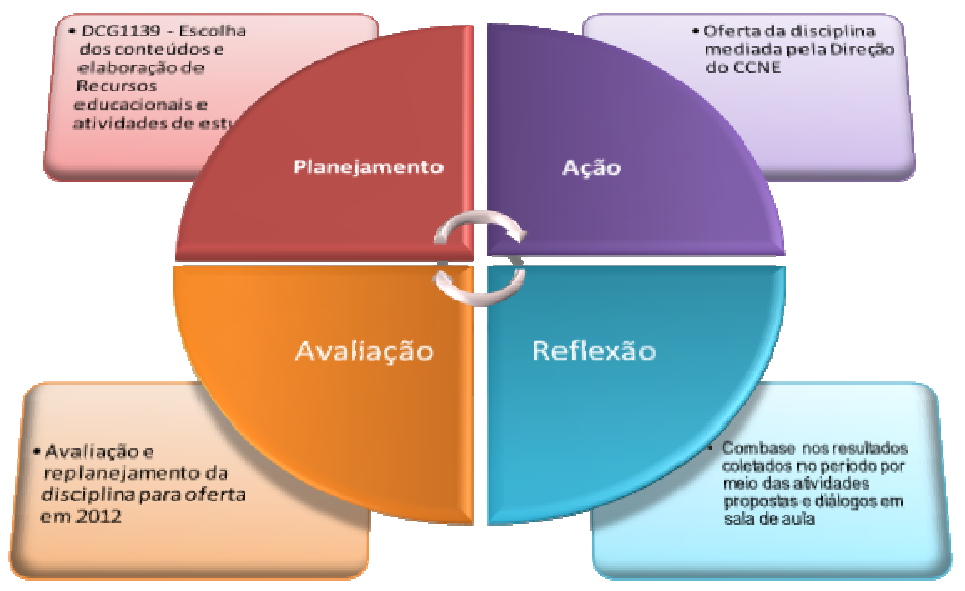

Figura 1 - Estratégia da Pesquisa-ação na DCG 1139.

Como instrumento de pesquisa foram propostas atividades individuais: a) questionário tipo survey com questões abertas e fechadas; b) depoimento no blog (turma 2 apenas) e atividade colaborativa Wiki nos períodos de agosto a setembro de 2011 (turma 1) e março a de abril de 2012 (turma 2). Após o encerramento do primeiro ciclo, as atividades questionário e Wiki foram reformuladas e replanejadas, na perspectiva da pesquisa-ação.

A disciplina complementar de graduação (DCG): Ciências Exatas e da Terra mediada por Tecnologias Educacionais em Rede, foi inicialmente ofertada no segundo semestre de 2011 (turma 1) para o Curso de Química Licenciatura na modalidade de ensino presencial, tendo 12 estudantes matriculados. A reoferta da DCG no primeiro semestre de 2012 foi ampliada para os cursos de licenciatura em física, geografia e química, tendo 15 estudantes matriculados (turma 2).

A DCG objetiva desenvolver competências e habilidades para a prática profissional, no âmbito das Ciências Naturais e Exatas, proporcionando fluência tecnológica, em especial nos ambientes virtuais de ensino-aprendizagem. A disciplina ocorre predominantemente no modelo presencial e suas atividades de estudo são planejadas, organizadas e realizadas no Moodle o qual funciona no endereço http://www.ufsm.br/moodle, com objetivo da construção da interatividade, interação, colaboração e autonomia do aprendizado. A metodologia de ensino-aprendizagem utilizada na disciplina viabilizou a prática educacional dialógico-problematizadora pautada nos 3 Momentos Pedagógicos - problematização inicial, organização do conhecimento e aplicação do conhecimento (Delizoicov; Angoti, 1993). Esses desafios organizam e estimulam a resolução de problemas.

A disciplina é composta por quatro unidades (módulos didáticos): 1- Ciência, Tecnologia e Sociedade, 2- Tecnologias Educacionais em Rede, 3- Portais Educacionais em Rede e 4 - Ambientes Virtuais de Ensino-aprendizagem. No decorrer dos módulos didáticos foram proporcionadas atividades de estudo individuais (envio de arquivo único, diário, texto online, enquete e questionário), bem como colaborativas (glossário, fórum, chat e wiki) com o objetivo de gerar desenvolvimento cognitivo dos estudantes, assim como proporcionar um diálogo a respeito da formação de professores para o uso das tecnologias. Neste trabalho nos focaremos no módulo 1: tópico fluência tecnológica. 


\section{Resultados e Discussão}

Desenvolver procedimentos metodológicos para integração das TIC no ensino de graduação e convergência entre as modalidades de educação presencial e a distância no ensino superior é essencial para produzir interdisciplinaridade entre as áreas do conhecimento. Os recursos educacionais disponibilizados na disciplina (Figura 2) possuem, em sua maioria, caráter hipermidiático proporcionando ao estudante uma leitura diferenciada com materiais dinâmicos, como vídeos e animações. 


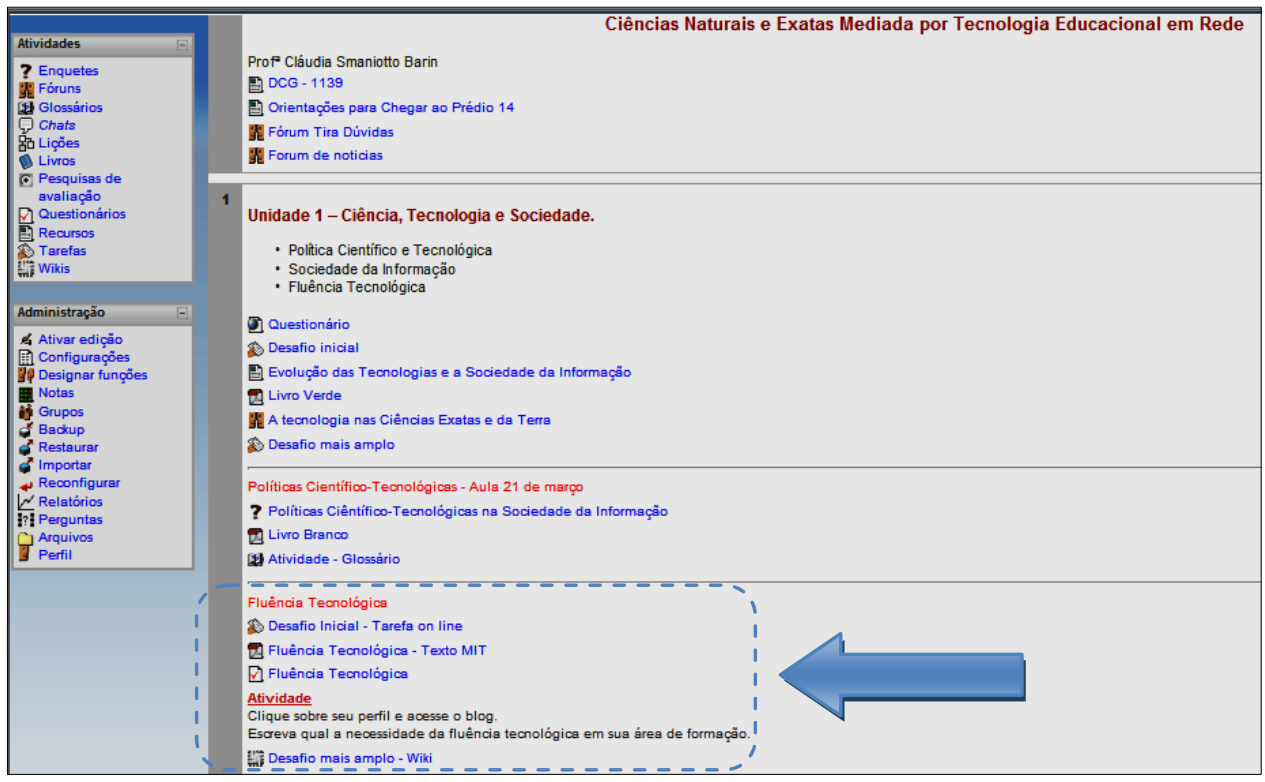

Figura 2 - Ambiente Virtual Moodle para a DCG1139 - Turma 2

O primeiro módulo didático abordou o tema Ciência, Tecnologia e Sociedade. No decorrer do módulo abordou-se a necessidade da fluência tecnológica para o uso efetivo das TIC para potencializar a aprendizagem dos estudantes, por meio da programação dos recursos educacionais e atividades de estudo.

O conceito de Fluência Tecnológica foi criado pela comissão de alfabetização digital da academia norte-americana de Ciências, segundo relata o Commitee (1999), originando-se na necessidade de suprir de conhecimentos e comportamentos adequados o estudante universitário para que este, não só venha a adquirir conhecimentos específicos de sua graduação, mas também, aprenda a reformular o conhecimento adquirido. Assim, a fluência tecnológica vai além de saber utilizar as ferramentas tecnológicas e implica em aprender novas formas de utilizar as ferramentas tecnológicas, de criar a partir destas e utilizar-se destas para aprender conceitos.

Com intuito de induzir os estudantes a reflexão sobre sua formação e práticas pedagógicas vivenciadas, disponibilizou-se uma atividade individual: questionário com perguntas abertas e fechadas, bem como a uma atividade no blog do Moodle, onde os estudantes teriam de refletir sobre a necessidade da fluência tecnológica para a sua área de formação, além da escrita colaborativa de texto na ferramenta de atividade Wiki sobre: a) A influência do desenvolvimento tecnológico na sociedade, b) O ensino na era tecnológica e c) Será necessário fluência tecnológica para ensinar nativos digitais?

\section{Questionário}

Os resultados obtidos em relação a fluência tecnológica quanto aos recursos da informática (Figura 3), demonstram que os estudantes não apresentam dificuldades no uso de editores de texto, mas são no entanto, mais fluentes nas ferramentas da internet. Estes dados são similares aos obtidos por Oliveira (2005) que observou o comportamento de estudantes em um laboratório de informática. 


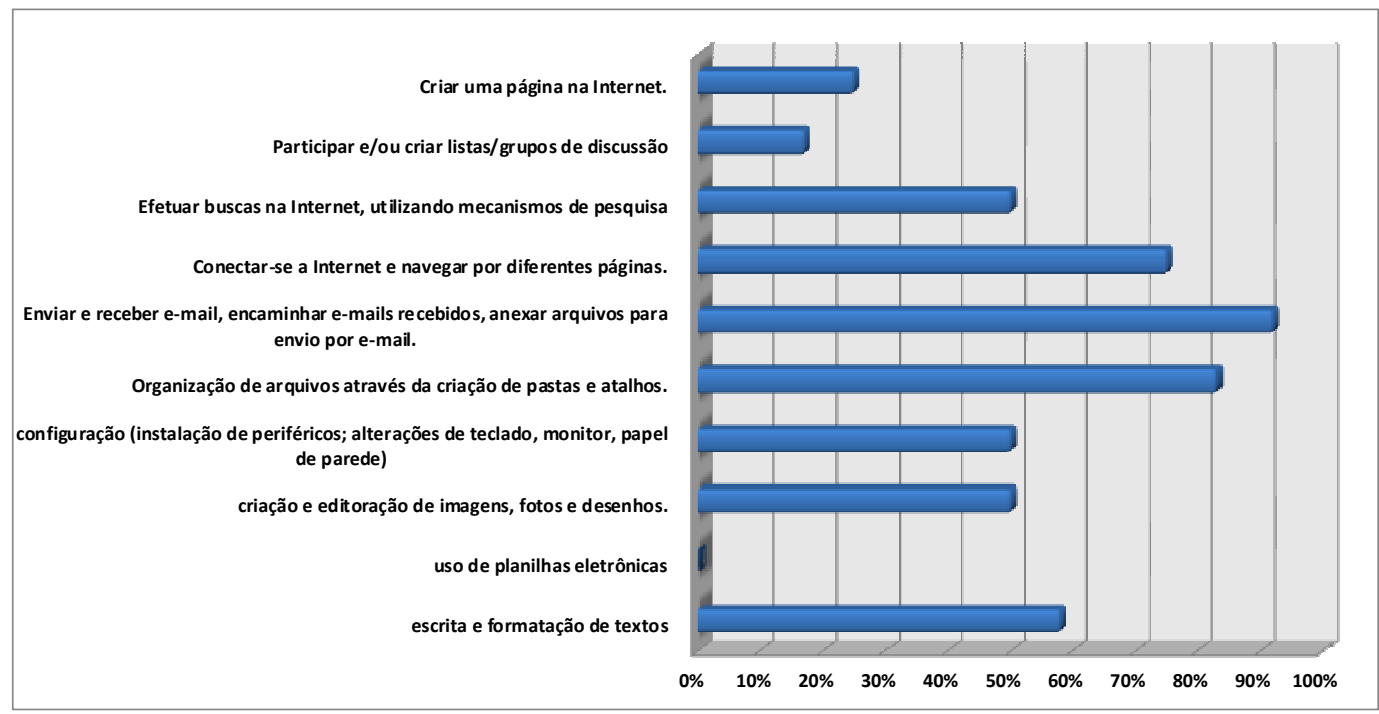

Figura 3 - Avaliação da fluência dos estudantes quanto aos recursos da informática.

Ainda com relação à fluência em recursos da informática, nenhum estudante relatou ser fluente no uso de planilhas. Este fato chama a atenção em virtude de $93 \%$ da turma ser composta por estudantes dos cursos de química e física que requerem raciocínio lógico-matemático e deveriam utilizar-se de planilhas para a elaboração de gráficos para avaliar situações no decorrer de suas disciplinas experimentais. Entretanto a dificuldade pode estar relacionada ao fato dos mesmos não serem orientados ao uso deste tipo de ferramenta, na sua formação acadêmica.

No questionamento posterior, os estudantes foram instigados a refletir sobre sua formação e se seu curso de graduação lhe proporciona a fluência tecnológica necessária para a atuação profissional (Figura 4).

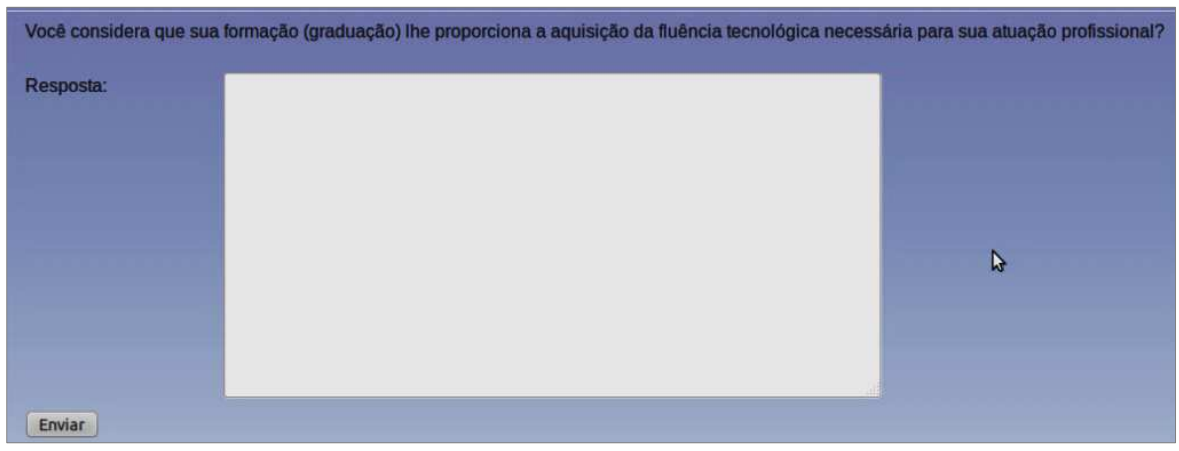

Figura 4 - Questão para reflexão sobre a formação dos estudantes para o uso das TIC em seu curso de graduação.

Os estudantes são unânimes em afirmar que a sua graduação não proporciona a fluência tecnológica, entretanto tem visão diferenciada sobre sua formação, conforme pode ser vislumbrado nas falas abaixo:

Acredito que não, pois o único recurso utilizado por professores, exceto o quadro e giz, é o datashow. Em uma única disciplina, cursada no início do curso, que utilizamos um programa para a construção de gráficos, na qual não me sinto fluente. Os professores não nos ensinam/preparam para trabalhar com as novas tecnologias. (Estudante $\mathrm{A}$ ) 
A graduação não proporciona a aquisição da fluência tecnológica, porém provê ao graduando o caminho para a aquisição dessa fluência. (Estudante B)

De forma geral, posso considerar que minha formação em nível de graduação, possuirá um déficit relacionado a Fluência tecnológica. Isso decorre pelo fato que, a maioria dos professores, não se utiliza de materiais tecnológicos em suas aulas. Quando isso ocorre, o mesmo não transmite aos alunos o modo pelo qual construiu aquela ferramenta, o que não proporciona aos alunos um desenvolvimento tecnológico. Além disso, apesar de alguns professores trabalharem com programas de computadores como auxilio em suas disciplinas, o mesmo possui dificuldade em manusear essas ferramentas, o que não garante uma fluência por parte dos alunos, pois os mesmos se encontram com uma formação atrasada e incompleta das reais necessidades. (Estudante C)

Com base nestas afirmações faz-se necessário refletir sobre: Quais as potenciais contribuições de competências em TIC para professores na atual situação da educação brasileira? A formação de professores para o uso das TIC lhes tem possibilitado desenvolver fluência tecnológica e pedagógica suficiente, a fim de propiciar uma educação tecnológica emancipatória? Por quais motivos seus professores não lhe proporcionam este aprendizado?

Após assistirem ao vídeo Tecnologia e Metodologia, compartilhado do repositório digital Youtube, os estudantes refletiram sobre a forma como as tecnologias da informação e comunicação têm sido utilizadas por seus professores no decorrer de seu curso de graduação.

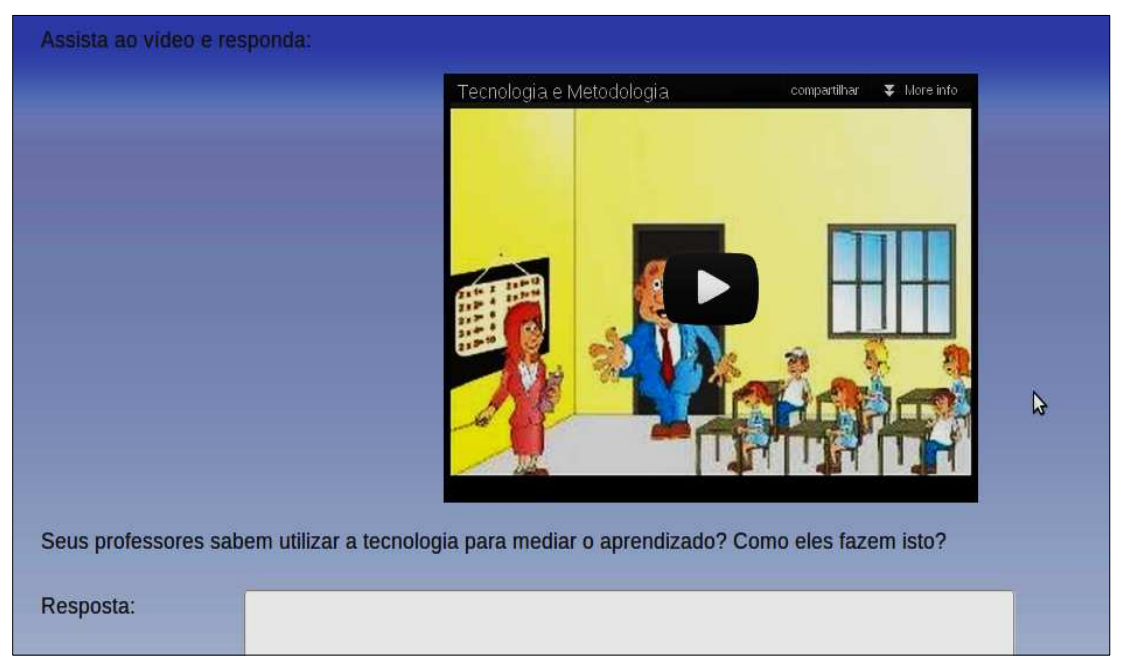

Figura 5 - Questão para reflexão sobre o uso das TIC pelos professores.

Em relação a este questionamento, os estudantes relatam que na maioria das vezes a tecnologia utilizada é o Datashow, mas que, no entanto ao invés de agregar informações o uso inadequado das TIC, torna a aula ainda mais cansativa. Os mesmos demostram preocupação com sua própria conduta enquanto futuros professores, pois temem repetir àquilo que lhes foi proporcionado.

Uma das estudantes relata ainda que a tarefa de mediar o ensino-aprendizagem é uma tarefa difícil para os professores se os mesmo não tiveram uma Formação Inicial com o uso de ferramentas tecnológicas: 
...percebe-se que a utilização destas ferramentas hoje pelos profissionais de educação é apenas para complementar o que já estava em andamento, ou seja, segue as metodologias de ensino que estavam sendo utilizados e apenas insere essas ferramentas como modo de chamar a atenção dos alunos para os conteúdos tradicionalmente trabalhados. (Estudante D)

A estudante relata ainda que o incremento de novas tecnologias nas escolas não é garantia de melhorias na qualidade de ensino, pelo contrário, pode apenas atrapalhar as aulas caso o professor não esteja preparado para receber tais mudanças. Assim, além do incremento destas novas ferramentas tecnológicas nas escolas, deve-se proporcionar aos professores uma Formação Continuada que garanta uma melhor preparação para essas novas mudanças.

\section{Blog}

Durante a abordagem do conceito de fluência tecnológica os estudantes foram provocados a escrever sobre a necessidade da aquisição da fluência em sua área de formação. Em algumas respostas pode-se perceber que os mesmos não haviam internalizado o significado de fluência, sendo este retomado antes da proposição de novas atividades. A maioria dos estudantes, no entanto, demostra compreender o que é fluência e como a mesma interfere em sua formação profissional. A figura abaixo (Figura 6) apresenta a visão de um dos estudantes do curso sobre a importância da fluência tecnológica para sua área de formação.

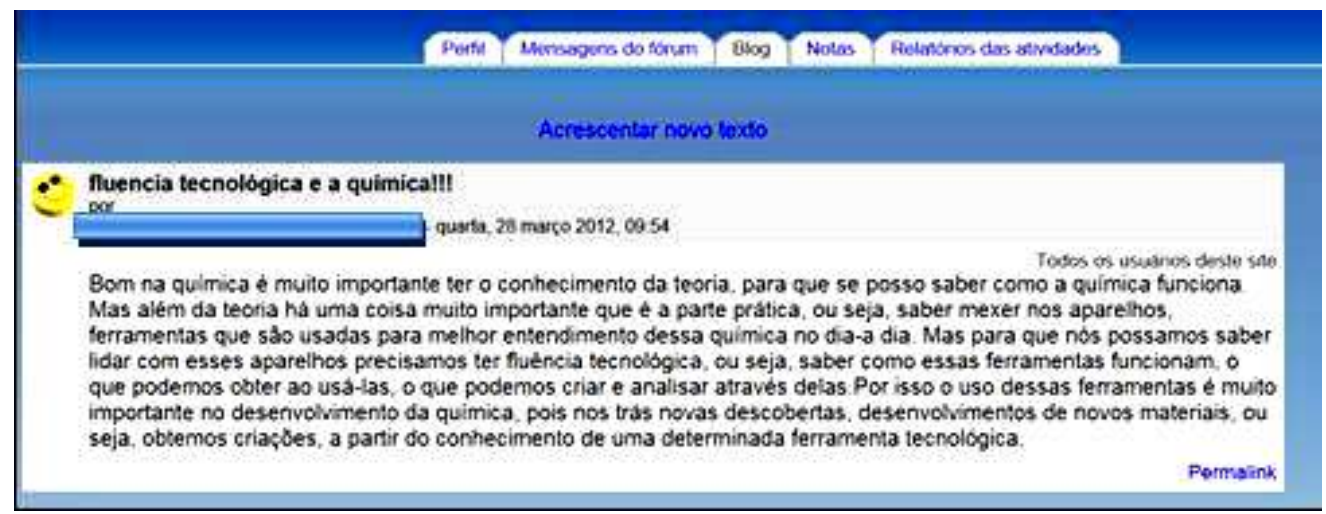

Figura 6 - Depoimento do "estudante E" sobre a necessidade da fluência tecnológica em sua área de formação, no Blog do Moodle.

Pelo relato observa-se que a fluência tecnológica vai além do processo de ensino-aprendizagem e perpassa a formação profissional. Isto demonstra que na atualidade, a aquisição da fluência deve ocorrer não apenas no decorrer da formação inicial do sujeito, mas de forma continuada ao longo de sua vida.

\section{Wiki}

No intuito de possibilitar a construção conjunta de um texto sobre a influência das TIC na sociedade e em especial na educação, disponibilizou-se no AVEA uma atividade colaborativa Wiki (Figura 7). 
Vamos construir de forma colaborativa um texto sobre a Fluência tecnológica e a Sociedade da Informação.

Visualizar Editar Links Histórico

Obrigada pela sua colaboração

\section{Desafio mais amplo - Wiki}

A influência do desenvolvimento tecnológico na sociedade

O ensino na era tecnológica

Será necessário fluência tecnológica para ensinar nativos digitais?

Figura 7 - Proposta de atividade colaborativa Wiki

Os estudantes da segunda turma da DCG 1139, (2012/1) demostraram maior facilidade na realização da atividade colaborativa, o que demonstra que, a mesma encontra-se melhor estruturada e que mesmo num curto período de tempo de acesso a plataforma de Moodle, os mesmos já transitam com fluência em algumas das ferramentas, sendo possível observar inclusive a inclusão de links externos para outros materiais.

Um dos textos elaborados pelos estudantes pode ser visualizado na Figura 8 abaixo. No texto observa-se a preocupação dos estudantes em estar preparados para a atuação docente em classes onde a maioria possua desde cedo a fluência no uso dos recursos da informação e da comunicação. Isto nos leva a reflexão de que o processo de formação de professores não pode ser estanque, que a formação deve se dar ao longo de toda a sua vida, que a formação inicial não é garantia de uma formação apropriada em mundo em constantes mudanças.

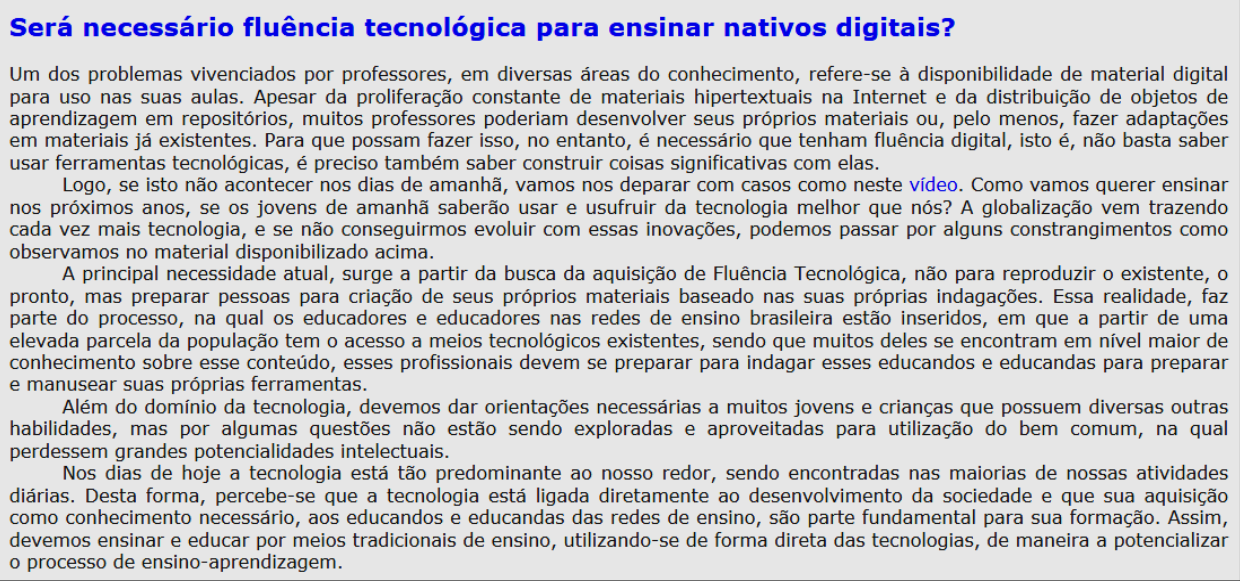

Um dos problemas vivenciados por professores, em diversas áreas do conhecimento, refere-se à disponibilidade de material digital para uso nas suas aulas. Apesar da proliferação constante de materiais hipertextuais na Internet e da distribuição de objetos de aprendizagem em repositorios, muitos professores poderiam desenvolver seus proprios materiais ou, pelo menos, fazer adaptações em materiais já existentes. Para que possam fazer isso, no entanto, é necessário que tenham fluência digital, isto é, não basta sabe usar ferramentas tecnológicas, é preciso também saber construir coisas significativas com elas.

Logo, se isto não acontecer nos dias de amanhã, vamos nos deparar com casos como neste vídeo. Como vamos querer ensinar nos próximos anos, se os jovens de amanhã saberão usar e usufruir da tecnologia melhor que nós? A globalização vem trazendo cada vez mais tecnologia, e se não conseguirmos evoluir com essas inovações, podemos passar por alguns constrangimentos como bservamos no material disponibilizado acima.

A principal necessidade atual, surge a partir da busca da aquisição de Fluência Tecnológica, não para reproduzir o existente, o pronto, mas preparar pessoas para criação de seus próprios materiais baseado nas suas próprias indagações. Essa realidade, faz parte do processo, na qual os educadores e educadores nas redes de ensino brasileira estão inseridos, em que a partir de uma elevada parcela da população tem o acesso a meios tecnológicos existentes, sendo que muitos deles se encontram em nivel maior de conhecimento sobre esse conteúdo, esses profissionais devem se preparar para indagar esses educandos e educandas para preparar manusear suas próprias ferramentas.

Além do domínio da tecnologia, devemos dar orientações necessárias a muitos jovens e crianças que possuem diversas outras habilidades, mas por algumas questões não estão sendo exploradas e aproveitadas para utilização do bem comum, na qua rdessem grandes potencialidades intelectuais.

Nos dias de hoje a tecnologia está tão predominante ao nosso redor, sendo encontradas nas maiorias de nossas atividades diárias. Desta forma, percebe-se que a tecnologia está ligada diretamente ao desenvolvimento da sociedade e que sua aquisição como conhecimento nessario, as educ o processo de ensino-aprendizagem.
a

Figura 8 - Texto elaborado de forma colaborativa por 5 estudantes da DCG 1139 (2012/1) na ferramenta de atividade Wiki. 


\section{Considerações Finais}

A análise dos dados obtidos não aponta para uma resposta definitiva, mas para outros questionamentos sobre as novas formas de aprender na sociedade da informação e da comunicação.

As atividades propostas levaram os estudantes a uma reflexão sobre sua formação e a necessidade da aquisição da fluência tecnológica, assim como do senso crítico para utilizar de forma apropriada os recursos da TIC como mediadores do processo de ensino aprendizagem, permitindo a flexibilização e a configuração de novas ecologias cognitivas.

A DCG 1139 vem proporcionando aos estudantes um ambiente dialógico para a discussão da aprendizagem mediada por tecnologias educacionais, possibilitando a aquisição da fluência tecnológica, principalmente no que se refere ao uso de ambientes virtuais de ensino-aprendizagem e ao uso de recursos educacionais abertos.

\section{Referências}

Barros, D.M.V.B. Guia didático sobre as tecnologias da comunicação e informação:material para o trabalho educativo na formação docente. Rio de Janeiro:Vieira \& Lent, 2009. 160p.

CITL (Committee on Information Technology Literacy). Being Fluent with Information Technology. National Academy of Sciences. Washington, D.C: National Academy Press, 1999.

Delizoicov, D.; Angotti, J. A. Metodologia do ensino de ciências. 2o ed. São Paulo: Editora Cortez, 1992.

França, G.. Os ambientes de aprendizagem na época da hipermídia e da educação a distância. Perspectivas em Ciências da Informação, v.14, n.1, p. 55-65, 2009.

Lévy, P.. Cibercultura. 7a ed. São Paulo: Editora 34, 2008.

Moran, J.M.; Masetto, M. T; Behres, M.A.. Novas tecnologias e mediação pedagógica. São Paulo: Papirus, 2000.

Oliveira, G.P.. Fluência Tecnológica, Comportamento e Complexidades: um Laboratório de Informática, o Tempo, as Pessoas e Outras Coisas. Ensaio: aval. pol. públ. Educ., v.13, n.48, p. 307-332, 2005

Ramos, A.F.; Nevado, R.A.; Del Pino, J.C.. Análise do projeto de licenciatura em química à distância da REGESD. Renote, v.4 n. 2, 2006.

Soffa, M.M.; Torres, P.L.. O processo ensino-aprendizagem mediado pelas tecnologias da informação e comunicação na formação de professores on-line. In: Anais do IX Congresso Nacional De Educação, EDUCERE, 2009

Valente, J.A. Computadores e Conhecimento: repensando a educação. Campinas: UNICAMP/NIED, 1993. 